\title{
La incidencia de la imagen de Grecia en la obra temprana de Hölderlin.
}

\author{
Impact of the image of Greece \\ on the early work of Hölderlin.
}

\author{
MANUEL BARRIOS CASARES \\ Universidad de Sevilla
}

Recibido: 22/06/2017 Aceptado: 19/12/2017

\section{RESUMEN}

Grecia funciona en el pensamiento de Hölderlin más como un paradigma intempestivo para articular la crítica del presente que como una referencia histórica destinada a suscitar el lamento elegíaco y la nostalgia del pasado. Y este modo tan singular de concebir la relación entre Grecia y la modernidad, discordante del modelo convencional de una filosofía de la historia, fecunda su búsqueda de una nueva ontología, capaz de rebasar los límites del kantismo, recogiendo sugerencias de Schiller o Fichte, a la vez que señalando sus insuficiencias. Para todo ello, la recepción de una lectura neoplatónica de Platón en el contexto de la filosofía de la Unificación resulta aquí decisiva.

\section{PALABRAS CLAVE \\ IDEALISMO ALEMÁN; HÖLDERLIN; GRECIA ; PLATONISMO; HEGEL}

\begin{abstract}
In Hölderlin's thinking, Greece works as an untimely paradigm that allows him to articulate the critique of the present, rather than as a historical reference, which would elicit the elegiac lament and the nostalgia of the past. And this singular understanding of the relation between Greece and modernity, wich is at odds with the conventional model of the philosophy of history, fertilizes his search for a new ontology — one that would be able to surpass the kantian limits, following suggestions by Schiller or Fichte while, at the same time, pointing out their insuffi-
\end{abstract}


ciencies. In this respect, it is decisive to properly understand the reception of a Neoplatonic reading of Plato in the context of the philosophy of Unification.

KEYWORDS

GERMAN IDEALISM; HÖLDERLIN; GREECE; PLATONISM; HEGEL

De LA AUTOCOMPRENSIÓN HISTÓRICA de la modernidad forma parte la idea de ser heredera del legado espiritual de la Antigüedad clásica. Ahora bien, esta relación no es sin más de continuación o mimética, como pudo figurarse la incipiente mentalidad renacentista. La tensión creciente entre el principio de la imitación de los griegos y la percepción del propio tiempo como inicio de una nueva era, tensión que va fraguándose a lo largo de la Querella de los antiguos y modernos y la Ilustración, eclosionará en la época de Goethe. En esa medida, son planteamientos insuficientes aquellos que tratan de entender el profundo influjo de la imagen idealizada de la antigua Grecia en la cultura alemana de finales del XVIII y principios del XIX en términos de mera nostalgia del pasado. Tampoco cabe reducirlo a simple recurso legitimatorio para el metarrelato de una modernidad naciente. En concreto, se argumentará en las páginas que siguen que la función de esta imagen de Grecia dentro del pensar poetizante de Hölderlin posee una dimensión mucho más profunda, y que esta dimensión, que en algún trabajo anterior hemos caracterizado en los términos de un «paradigma intempestivo de la modernidad ${ }^{1}$, puede rastrearse ya en su obra temprana.

En todo caso, cabría decir que la modernidad se muestra como una conciencia arruinada de Grecia que, sabedora de la imposibilidad de restaurarla, se constituye en la tensión y diferencia con ella. En Schiller o en Hegel lo hace para promover un movimiento de superación, para ir más allá de ella. Grecia será para el Hegel de madurez un pasado que ya ha revelado y agotado por completo sus posibilidades. No así en Hölderlin. Para el poeta, Grecia es insuperable. Ahora bien, no lo es debido a una fijación clasicista, ni tampoco por los motivos aducidos por Georg Lukács en su estudio sobre el Hyperion, al reconstruir el perfil político de Hölderlin como el de un pensador del periodo revolucionario de la burguesía que se habría quedado atrapado en el momento ideológico de una falsa conciencia burguesa respecto a sus aspiraciones reales (no la emancipación de la humanidad, sino su propio ascenso al poder) y que, en consecuencia, habría quedado prisionero de esa imagen legendaria de Grecia como coartada ideológica para la nostalgia mística y el impotente luto elegíaco ${ }^{2}$.

1 Cfr. Manuel Barrios, Hölderlin y Nietzsche, dos paradigmas intempestivos de la modernidad en contacto. Sevilla: Reflexión / Universidad de Sevilla, 1992.

2 G. Lukács, «El Hyperion de Hölderlin» (1934), en Goethe y su época, trad. de M. 
Esta reconstrucción resulta unilateral y forzada, reduce la problematicidad interna de la relación entre Grecia y la modernidad al molde de una filosofía de la historia cortada según el patrón dialéctico más esquemático, cuando lo cierto es que lo insuperable de la grecidad posee otro sentido en Hölderlin, en tanto que inasumible dentro una concepción de la Historia como mera linealidad progresiva ${ }^{3}$. Probablemente es cierto, como ha escrito Félix de Azúa, que Hölderlin conocía de modo tan íntimo a la antigua Hélade y comprendía tan a fondo su legado, que por eso «sabía perfectamente que la hermosa Grecia nunca había existido, sino que más bien Occidente había construido el mito griego para que su propio destino viniera de algún lugar y fuera hacia alguna parte». ${ }^{4}$

Sueño y lamento de un Occidente moderno necesitado de reinventar su procedencia y su destino, ciertamente, la imagen de la Grecia clásica alimenta la insatisfacción con el presente, ofreciendo contramodelos: así el de una paideia basada en el ideal de la kalokagathía; el de una protodemocracia; el de una razón liberada de la superstición pero reconciliada con el sentimiento; el de una comunidad donde arte, ética y religión van unidas; el de una vida en sintonía con la naturaleza; el de un equilibrio de las facultades humanas: Grecia, en definitiva, es el recurso arbitrado por los modernos para poder conformar la imagen de una totalidad no desgarrada. Y de esos contramodelos se nutren tanto clasicismo como romanticismo. El primero, para proponerla como paradigma suprahistórico; el segundo, combinando escatología e historia, para basar en ella el presagio de una inminente consumación de los tiempos.

Pero ya en Schiller - así en su poema Los dioses de Grecia, original de 1788 - toda referencia a la antigua Hélade suena a recuerdo y despedida, de manera que el carácter definitivamente irrecuperable del mundo griego invita a explorar otro camino, un camino que devuelva su viveza a «la palabra desalmada $»^{5}$ del presente, corrija su extravío y enderece el rumbo hacia la realización de aquel ideal que los helenos proyectaron en sus mitos.

El Hiperión de Hölderlin, ese «ensayo de novela griega» ${ }^{6}$ cuyos primeros esbozos datan de la época de finalización de sus estudios en el seminario evan-

Sacristán. Barcelona: Grijalbo, 1968, pp. 213-238.

3 Vid. Volker Rühle, «'Un aspecto poético de la historia'. Experiencia del tiempo y elaboración poética en Hölderlin», en: J. A. Marín-Casanova, El fin del mal. Teodicea y filosofía de la Historia desde el idealismo alemán. Sevilla: revista Reflexión, 3 (2000), pp. 87-114.

4 Félix de Azúa, «Perder lo que nunca fue nuestro», El País, 3 de enero de 2012.

5 Friedrich Schiller, «Los dioses de Grecia»; en Seis poemas "filosóficos» y Cuatro textos sobre la dramaturgia y la tragedia. Trad. de Martin Zubiria y Josep Montaner. Valencia: MUVIM, 2005, p. 28.

6 Carta de Hölderlin a Neuffer, Tubinga, 21/23 de julio de 1793; en Hölderlin Sämtliche Werke und Briefe (= SWB). 2 vols. Edición de Günter Mieth. Darmstadt: WB, 1989, vol. II, p. 564. Cfr. Hölderlin, Correspondencia completa $(=\mathrm{HCC})$. Trad. de Helena Cortés y Arturo Leyte. 
gélico de Tubinga, en torno a 1793, en contacto con Schiller, también parte de ahí ${ }^{7}$. Y para situarnos plenamente en contexto, recordemos lo que desde Walterhausen, recién salido del seminario, escribe Hölderlin el 10 de julio de 1794 a su amigo Hegel, que por aquel entonces se encuentra en Berna:

«Mi trabajo está ahora muy concentrado. Kant y los griegos son casi mis únicas lecturas. Sobre todo trato de familiarizarme con la parte estética de la filosofía crítica». ${ }^{8}$

Así que Kant, sobre todo el Kant de la Crítica de la facultad de juzgar, y los griegos. Pero ¿qué griegos son ésos que el poeta lee con tanta concentración mientras redacta la primera versión de su novela? Se sabe por sus trabajos escolares que Hölderlin frecuentaba a los trágicos griegos, a Píndaro, a Homero y a Hesíodo. Pero hay una pista que nos permite responder a esta pregunta de un modo mucho más preciso. Basta considerar que, justo tres meses después, en una carta a su amigo Neuffer, en la que le anuncia la pronta publicación del Fragmento de Hiperión en la revista Nueva Talía de Schiller y le cuenta que ha estado trabajando todo el verano en la primera parte de una nueva versión, Hölderlin añade:

«Tal vez pueda mandarte un ensayo sobre las ideas estéticas, porque puede pasar como un comentario al Fedro de Platón y mi texto es expresamente un pasaje del mismo, de manera que quizá le sea útil a Conz. En realidad, pretende contener un análisis de lo bello y lo sublime a partir del cual resulte más sencillo el de Kant y ofrezca mayor variedad de perspectivas, como en parte ha hecho ya Schiller en su escrito Sobre gracia y dignidad, aunque atreviéndose a pasar la línea fronteriza de Kant un punto menos de lo que, en mi opinión, debería haberse atrevido». ${ }^{9}$

Así pues, al joven Hölderlin le interesa desarrollar la parte estética de la filosofía kantiana según una peculiar modulación, que recoge el testigo de Schiller para procurar superarlo recurriendo de forma expresa y directa a Platón. Una

Madrid: Hiperión, 1990, p. 149.

7 Vid. su poema Grecia, primera versión, de 1793, vv.41-56: «Ática, la gigante, ha caído. // Donde descansaban los antiguos hijos de los dioses, // en las ruinas de los palacios de mármol // se cierne ahora una eterna quietud de muerte. // Sonriendo desciende la dulce primavera, // pero nunca más hallará a sus hermanos// en el santo valle del Illiso: // el ansioso desiero los cubre por siempre. // El deseo me impulsa hacia aquel país mejor, // hacia Alceo y Anacreonte, // y quisiera dormir en la estrecha morada/ / junto a los santos de Maratón // ¡Que ésta sea la última de mis lágrimas // vertidas por la querida Grecia!/ / Haced sonar, Parcas, vuestras tijeras, // pues mi corazón pertenece a los muertos» (SWB, I, 162-163).

8 SWB, II, 610; cfr. HCC, 199.

9 SWB, II, 620.; cfr. Correspondencia completa, ed. cit., p. 211. 
asociación nada infrecuente en su caso. Años más tarde, Neuffer comentaría, a propósito de los Himnos de la época de Tubinga, que éstos «habían surgido de un enorme esfuerzo por revestir con el traje del arte poético las ideas abstractas, en particular las de Platón y Kant». ${ }^{10}$ Y la mención a Carl Philipp Conz, profesor en el Seminario tubingués, famoso en clase por sus inspiradoras lecturas de algunos diálogos platónicos y, en particular, por parafrasear ampliamente el Fedro,$^{11}$ además de ser alguien que coincide con Hölderlin en el propósito de conferir revestimiento poético a las ideas filosóficas --tal como atestiguan las distintas versiones de su poema El alma, publicadas también en la revista Nueva Talía en 1792 y $1793^{12}$ - constituye una prueba más de la importante presencia de Platón en la orientación primera del pensamiento hölderliniano.

El programa filosófico del joven Hölderlin está, por tanto, bien definido en estas breves líneas de su carta a Neuffer de 1794: se trata, aunque sea con Kant, de ir más allá de Kant - y más allá de lo que el propio Schiller ha sido capaz de ir en este empeño. Ir más allá puede suponer en este caso conjugar a Kant y los griegos, Grecia y Modernidad, pero de un modo tal que resuelva las rígidas fronteras entre teoría y praxis trazadas por el criticismo. En esa medida, nos parecen erróneas esas lecturas del Fragmento de Hiperión que insisten en una estricta observancia del kantismo en el joven Hölderlin. En su estudio sobre la amistad intelectual compartida por Hegel, Hölderlin y Schelling durante sus años de juventud, Christoph Jamme afirma, por ejemplo, que el prefacio teorético del Fragmento es un producto «inequívocamente impregnado de dualismo kantiano» ${ }^{13}$; y en su monumental trabajo sobre los orígenes de la dialéctica, Panajotis Kondylis comenta el ensayo hölderliniano de 1794, Sobre la ley de la libertad, desatendiendo nociones tan significativas que aparecen en él como «Moralität des Instinkts» 0 «die Hilfe der Natur», al considerarlas meros apuntes de una constelación de pensamiento que aún está por venir ${ }^{14}$; es decir, en el fondo, como si no estuvieran ya ahí.

Pero ése es el problema: que Hölderlin, incluso cuando en el citado ensayo dice que el estado natural de apetencia no es aún un estado moral y que, por

10 Hölderlin-Texturen, 2: Das «Jenaische Project». Wintersemester 1794/95, mit Vorbereitung und Nachlese. Tübingen: Hölderlin-Gesellschaft, 1995, 21.

11 Así lo hace en su trabajo Schicksale der Seelenwanderungshypothese unter verschiedenen Völkern und in verschiedenen Zeiten, Königsberg 1791.

12 Carl Philip Conz, Die Seele. Fragment eines größeren Gedichts (en: Thalia, Segunda parte, Cuarta entrega del año 1792, pp. 26-39); y Die Seele, ein philosophisches Gedicht in drey Gesängen (en: Thalia, Cuarta parte, cuarta entrega del año 1793, pp. 34-52).

13 Christoph Jamme, „Ein ungelehrtes Buch”. Die philosophische Gemeinschaft zwischen Hölderlin und Hegel in Frankfurt 1797-1800. Bonn: Bouvier, 1983, p. 75.

14 Panajotis Kondylis, Die Entstehung der Dialektik. Eine Analyse der geistigen Entwicklung von Hölderlin, Schelling und Hegel bis 1802. Stuttgart: Klett-Cotta, 1979, p. 262. 
consiguiente, la ley de la libertad debe mandar sin considerar si cuenta o no con el auxilio de la naturaleza; incluso cuando en el prefacio del Fragmento de Hiperión dice que es la «libre voluntad ${ }^{15}$ de cada uno la que debe decidir el camino a seguir, desde el ideal de máxima simplicidad al de suma cultura, aun así, mantiene discrepancias con la estricta letra del kantismo.

De hecho, la novela no nos ilustra sobre un tipo de travesía moral del héroe según los parámetros del puro deber kantiano: la búsqueda de la verdad, el sueño de la fraternidad de los hombres pueden manifestar huellas de la razón práctica - en cuanto ideales que no se alcanzan plenamente en esta vida; pero no en la manera en que Hiperión marcha hacia ellos, siguiendo los impulsos de su corazón o combinando amor y deber en su relación con Melita-Diotima; ni tampoco al final del relato, cuando el sentimiento de reencuentro con la Naturaleza es lo que le reconcilia con el fracaso de sus aspiraciones y lo incita a seguir perseverando con una mirada más trágica, consciente ahora de la imposibilidad de conciliación plena de ideal de cultura e ideal de naturaleza en el ciclo de la vida del hombre.

En cuanto al ensayo de 1794, resulta innegable que el joven Hölderlin atisba ya en esta época otra dimensión de lo real, no necesariamente escindida, y, con ello, otra idea de naturaleza, como la que pronto va a proclamar su colega Schelling en sintonía con la atmósfera panteísta del momento ${ }^{16}$. Por eso escribe ahí: «Hay una cara de la facultad de apetecer empírica, la analogía de lo que se llama naturaleza, la cual es chocante en el más alto grado, donde parece hermanarse la necesidad con la libertad, lo condicionado con lo incondicionado, lo sensible con lo sagrado, una inocencia natural, podría decirse una moralidad del instinto, y la fantasía acorde con ello es celeste». ${ }^{17}$

Claro que, siendo un estado natural, dependerá de causas naturales y, en tanto en cuanto explicable por el mero mecanismo de la causalidad eficiente --según ha advertido F. H. Jacobi en sus Cartas sobre la doctrina de Spinoza, detonantes de la polémica del panteísmo-- no habría verdadera libertad en este plano. El milagro griego, el de cómo los griegos lograron armonizar instinto

15 F. Hölderlin, Fragmento de Hiperión. Edición de Manuel Barrios. Sevilla: Athenaica, 2016, p. 47.

16 Vid. Carta de Schelling a Hegel, fechada en Tubinga la noche de Reyes de 1795, en la que le escribe: «Mi vida es la filosofía en este momento. La filosofía no se halla aún terminada. Kant ha dado los resultados, las premisas siguen faltando (...). Tenemos que ir aún más lejos con la filosofía (...). Fichte llevará a la filosofía a una altura que va a dar vértigo incluso a la mayoría de los actuales kantianos... Actualmente trabajo en una ética a lo Spinoza. Sentaré los primeros principios de toda filosofía, en los cuales se unen la razón teórica y la práctica» (Hegel, Escritos de juventud (= HEJ). Ed. de J. M ${ }^{a}$ Ripalda. Madrid: FCE, 1978, p. 53).

17 SWB, I, 835; cfr. Ensayos. Ed. de Felipe Martínez Marzoa. Madrid: Peralta/Ayuso, 1976, pp. 19 
y moralidad, es algo que no parece tener explicación en principio. Y sigue al menos sin tenerla dentro del esquema estricto del kantismo. Sin embargo, cada vez que Hölderlin se remite a Grecia, ve ese milagro, capta ese hermanamiento supuestamente imposible ${ }^{18}$. Y lo ve sobre todo cuando recurre a Platón: he aquí la clave a la que antes aludimos. Porque Platón, ese patrón del dualismo metafísico según Nietzsche, va a ser leído de forma esencialmente no dualista por los jóvenes idealistas de Tubinga, que apelarán fundamentalmente a los diálogos del entusiasmo -- Banquete, Fedro -- para poner el acento en el papel mediador de eros entre los llamados «dos mundos». Para ellos, Platón es, por tanto, el pensador que expresa en forma poética un sistema filosófico coherente con la imagen de Grecia como paradigma de una totalidad no desgarrada.

No nos es posible detallar, en el breve espacio de un artículo, los pormenores de esta rica recepción de Platón en el idealismo alemán. ${ }^{19}$ Baste indicar algunos hitos fundamentales relativos a su presencia en el ideario del círculo de Tubinga, en concreto dentro de esa constelación de pensamiento que acabará conformando lo que los especialistas conocen como «filosofía de la unificación» (Vereinigungsphilosophie). Para ello conviene tener presente, en primer lugar, que, en la Alemania dieciochesca, antes de la edición casi completa de los diálogos platónicos llevada a cabo por Schleiermacher, Platón fue conocido principalmente a través de la traducción latina de sus textos realizada en el Quatrocentto por Marsilio Ficino ${ }^{20}$. Gracias al registro de préstamos de la biblioteca del seminario de Tubinga, sabemos que Hölderlin leyó durante sus años de estudio allí La República, Minos y El Político en la edición de la Academia platónica de Florencia comentada por Ficino ${ }^{21}$; y que en la revista Nueva

18 La categoría de "milagro" no es aquí anecdótica. El Hegel frankfurtiano la emplea expresamente, al hilo del Fedro, para referirse al modo en que el amado es uno con el ser del amante (HEJ, 243). Su función es la propia de una intuición intelectual que transciende la oposición de términos aparentemente separados entre sí.

19 Para un estudio exhaustivo de esta influencia, vid. Jean-Louis Vieillard-Baron, Platon et l'idéalisme allemand (1770-1830). París: Beauchesne, 1979. Así como también el libro de Christian Asmuth, Interpretation - Transformation. Das Platonbild bei Fichte, Schelling, Hegel, Schleiermacher und Schopenhauer und das Legitimationsproblem der Philosophiegeschichte. Göttingen: Vandenhoeck \& Ruprecht, 2006.

20 Desde la edición frankfurtiana de 1602 (Plato Opera Omnia, tr. gr. et lat. Marsilio Ficini interprete, Francofurti, C. Marnium et haeredes), no hubo en Alemania otra edición hasta la bipontina de 1781 .

21 Según ha mostrado Michael Franz en su artículo «Platons frommer Garten. Hölderlins Lektüre von Tübingen bis Jena», en Hölderlin-Jahrbuch, 28 (1992-93), pp. 111-127, al intercambiar los ríos Cefiso e Iliso en las distintas versiones de su poema Grecia para que ambos lugares coincidieran simbólicamente, Hölderlin no hacía sino repetir lo que ya Ficino había hecho en su comentario al Fedro, leyendo el pasaje inicial del diálogo, que transcurre a orillas del Iliso, al sureste de Atenas, como una alegoría de la Academia platónica, situada junto al Cefiso, en el 
Talía de Schiller, tan cercana a él, se publicó en 1792 una traducción anónima de El banquete, probablemente obra de Inmanuel Niethammer, además de la primera versión del poema de Conz, Die Seele, ya referido antes. Este Platón del entusiasmo, mediado por la recepción neoplatónica de la Academia de Florencia ${ }^{22}$, combinado con la mística alemana por Jakob Böhme y Oetinger, así como con Bruno y Spinoza, revitalizado por el neoplatonismo inglés y el del círculo de Münster, es el que llega fundamentalmente hasta Hölderlin. Se trata de un Platón más místico que racionalista, bien distinto al ideal kantiano de filósofo ${ }^{23}$, en el que ideas fundamentales como las del Bien, la Belleza, el Alma del mundo o el Amor se presentan con un acusado sesgo neoplatónico, para sugerir una visión estética de la totalidad del universo que cancela y supera la limitada mirada del intelecto. Nociones de clara impronta platónica, pasadas por el tamiz de lecturas neoplatónicas bien diversas -- Plotino, pero también Proclo, Ficino, Shastesbury o Hemsterhuis, entre otros -- confieren así singular complejidad y espesor especulativo a esta recepción, tan rica en consecuencias. $\mathrm{Su}$ influencia nos parece decisiva a la hora de articular esa concepción del ser como unidad en la multiplicidad que gravita en el proyecto hölderliniano de rebasar el kantismo ${ }^{24}$.

Pues, en efecto, en correspondencia asimismo con la tradición indirecta y las doctrinas no escritas de Platón (una correspondencia ésta que merecería un estudio más específico), Hölderlin nos habla de un Ser que es Uno y lo concibe como algo previo a los entes, que no serían sino el resultado de un desdoblamiento posterior, i. e., de la mezcla de dos principios: unidad y multiplicidad, peras y apeiron, grande y pequeño. Y, al igual que Platón, piensa que el amor, en tanto deseo de unión, despierta en el alma el recuerdo de un estado anterior a la caída, entendida ésta como caída en la individuación, en la separación, es decir, en el mundo tal como es para el entendimiento.

Mediante estas pistas estamos en condiciones de comprender mejor cómo trata Hölderlin de ir más allá de la línea fronteriza kantiana. Se ve claramente que quiere reformular aquello que en su tiempo se expresa como un rígido

norte de la ciudad.

22 Así por su Platonica Theologia de animarum immortalitate (1474).

23 Y recuérdese que pronto Kant, en su opúsculo De un elevado tono de distinción adoptado recientemente en filosofía, iba a llamar a Platón el padre de toda Schwärmerei (toda exaltación o delirio visionario; aunque distinga al Platón Académico del Platón místico de las Cartas).

24 La fórmula heraclítea hen diapheron eauto (lo uno diferente a sí mismo), mencionada por Platón en El banquete, será empleada a menudo por los jóvenes idealistas, y de ella se afirma en Hiperión, o el eremita en Grecia: Sólo un griego podía haber hallado la gran frase de Heráclito, hen diapheron eautó (lo Uno diferenciado en sí mismo), pues es la esencia de la belleza y antes de que se descubriera eso no había filosofía alguna (SWB, I, 659-660; cfr. Hiperión. Trad. de J. Munarriz. Madrid: Hiperión, 1993, p. 116. 
dualismo sin mediaciones: la realidad fenoménica de un mundo sometido a la causalidad eficiente, a la necesidad, por un lado; y el ideal nouménico de la libertad del hombre, por otro. Quiere, pues, conciliar a Kant y los griegos, o sea, la conciencia finita moderna y aquel Uno-todo (Hen kai pan) spinoziano, que las advertencias de Jacobi no han hecho sino poner aún más de moda entre la joven generación idealista. Y Platón, del lado de Spinoza más que del de Kant, resulta ser la inspiración fundamental.

Guiado por esta lectura de Platón en clave no dualista, Hölderlin procurará desde bien temprano pensar ese Ser que es Uno-Todo; pero no meramente al modo de un difuso panteísmo, donde se suprime el más allá y sólo queda un mundo donde cada cosa singular sería en sí misma algo divino, en una suerte de «monismo orientalizante», del que también Hegel se burlará reiteradas veces. El camino de Hölderlin hacia los dioses no se compagina bien con una lectura secularizadora tan unilateral. Consciente de lo insatisfactorio de todo intento de acceder a ese Ser superior por la mera vía del entendimiento y la conciencia reflexiva (i. e., por vía de lo que el Hegel de Fe y saber llamará «filosofía de la reflexión»), es Hölderlin el primero de los tres amigos de Tubinga que, tras asistir desde noviembre de 1794 a las clases de Fichte en Jena, estampa en abril de 1795, en la solapa de su ejemplar de la Grundlage der gesammten Wissenschaftslehre fichteana, una crítica a la autoposición del yo como lo absolutamente primero. Nos estamos refiriendo al fragmento ensayístico conocido como Juicio y Ser (o Ser, Juicio, posibilidad, según el orden de párrafos sugerido por Dieter Henrich), donde se lee:

«Ser expresa la conjunción de sujeto y objeto.

Allí donde sujeto y objeto no están unidos sólo de manera parcial, sino que están unidos pura y simplemente de tal manera que no puede efectuarse ninguna partición sin dañar la esencia de aquello que debe ser separado, allí y en ningún otro lugar puede hablarse de un ser pura y simplemente (Sein schlechthin), como ocurre en el caso de la intuición intelectual.

Pero este ser no debe ser confundido con la identidad. Cuando digo «yo soy yo», el sujeto (yo) y el objeto (yo) no están unidos de tal manera que ninguna separación pueda ser efectuada sin dañar la esencia de aquello que debe ser separado: al contrario, el yo sólo es posible por medio de esta separación del Yo respecto al Yo. ¿Cómo puedo decir '¡yo!' sin autoconciencia? Pero, ¿cómo es posible la autoconciencia? Es posible porque me contrapongo a mí mismo, porque me separo de mí mismo, pero, sin tener en cuenta esa separación, me reconozco como lo mismo en aquello que está contrapuesto. ¿Pero en qué medida como lo mismo? Puedo, tengo que preguntar así; porque desde otro punto de vista eso está contrapuesto a sí 
mismo. Por lo tanto, la identidad no es una unión del objeto y el sujeto que tuviera lugar pura y simplemente; por lo tanto, la identidad no es igual al ser absoluto» ${ }^{25}$.

El texto, tomado a menudo como una crítica a Fichte, convendría interpretarlo más bien como testimonio de la ambivalencia con la que Hölderlin considera el intento fichteano de superar el kantismo desde dentro. Ambivalencia favorecida en gran parte por el hecho de leer dicho intento a la luz de la exigencia de Jacobi de adoptar un punto de partida en lo incondicionado ${ }^{26}$. A fin de cuentas, Fichte no pretende propiamente establecer un principio sustantivo, ni partir de un factum, de un hecho de conciencia, sino generar más bien, en el espacio mismo de análisis de la unidad de la conciencia planteado por Kant, el movimiento en virtud del cual el Yo puede constituirse en motor de su autodeterminación. A eso apunta la Tathandlung fichteana: a un rebasamiento del plano meramente teórico, establecido hasta ahora como punto de partida de la filosofía transcendental, para alumbrar la genuina dimensión práctica, activa, del yo. En esa medida, hay también en Fichte elementos para una crítica al modelo reflexivo de la autoconciencia. Hölderlin no haría, pues, sino extraer las últimas consecuencias de esta crítica. Lo que ocurre es que la propuesta de una nueva forma de concebir la deductibilidad, que Fichte comienza a desarrollar en sus apuntes especulativos a su llegada a Jena, choca frontalmente con el abandono de toda posibilidad de deducción a partir de un principio incondicionado, abandono que Reinhold había comunicado a sus alumnos poco antes de su partida de esa Universidad; y esta circunstancia es la que viene a suscitar el recelo de unos estudiantes jenenses que, avisados del giro escéptico reinholdiano, entonces, sin contexto claro de recepción, entienden que Fichte pretende superar con su Yo $=$ Yo toda división y toda limitación, estableciendo un fundamento absoluto de la experiencia. En realidad, Fichte busca mantenerse en un punto de vista, el de la filosofía transcendental, cuyo abandono es el joven Schelling quien lo está anunciando con su escrito de 1795 Del yo como principio de la filosofía y su postulación de un absoluto de signo spinoziano. De ahí la ambivalencia con la que Hölderlin se refiere a Fichte en las cartas a Hegel de su etapa jenense, donde tan pronto le atribuye rasgos propios de un «dogmático» y un «metafísico» ${ }^{27}$, por pretender supuestamente derivar toda filosofía de un Grundsatz, como adivina en él un punto escéptico. De ahí también que su reticencia conviva con un claro

25 SWB, I, 840-841; cfr. Ensayos. Ed. de Felipe Martínez Marzoa. Madrid: Peralta/ Ayuso, 1976, p. 26.

26 Sobre esta cuestión, Dieter Henrich, Der Grund in Bewusstsein. Untersuchungen zu Hölderlins Denken (1794-1795). Stuttgart: Klett-Cotta, 2º ed., 2004.

27 SWB, II, 639; HCC, 232: carta de Hölderlin a Hegel, escrita desde Jena el 26 de enero de 1795 . 
interés por otros aspectos del pensamiento fichteano, como por ejemplo «su curiosa forma de tratar la determinación recíproca del yo y el no-yo. O también la idea de aspiración ${ }^{28}$, aspectos en el fondo asumidos por Hölderlin justo para oponerse a la consideración del Yo como un principio absoluto efectivamente existente, donde las divisiones habrían quedado resueltas de hecho.

Con todas estas ambigüedades, Hölderlin concluye que el modelo reflexivo de la autoconciencia no puede identificarse con esa unión más íntima de todo lo viviente a la que se refiere en su ensayo con la expresión «Sein schlechthin», ni, por tanto, puede valer como fundamento de toda experiencia. Lo que supondrá a la postre una invitación a pensar el yo más allá de la estructura cerrada y monológica de la vieja res cogitans. De este modo, lo que viene a sentenciar el fragmento Juicio y Ser es, en definitiva, que no cabe reificar el yo, haciendo de él una sustancia. La identidad reflexiva de la autoconciencia, que quiere ponerse como primera y absoluta, proviene en realidad de un previo desdoblamiento sujeto-objeto, tal como se expresa en el juicio (Ur-theilung, "partición originaria», según la falsa etimología aprovechada por el poeta). Sin duda, Hölderlin anticipa aquí aspectos de la crítica hegeliana a la proposición del entendimiento del Prólogo de la Fenomenología del Espíritu. Y al concebir un Ser como unidad prerreflexiva, no determinada por la separación de sujeto-predicado, que no se agota en las escisiones ni se somete a la cadena de lo condicionado, ilumina, aun con todas las insuficiencias que luego serán advertidas tanto por Hegel como por él mismo, la trayectoria subsiguiente del idealismo alemán a partir de una inspiración de fuerte cariz neoplatónico.

En esta primera etapa jenense, Hölderlin todavía se debatirá entre soluciones insatisfactorias, como es el caso del intento fichteano de resolver las escisiones en el Yo absoluto. Conforme vaya madurando su concepción, Hölderlin irá comprendiendo de forma cada vez más clara que ese Ser no puede darse en presencia -- de modo óntico, vale decir -- que la «unificación con todo cuanto vive» sólo es susceptible de ser captada a través de la separación de las partes. Con ello, en el fondo, su posición a este respecto no va a diferir tanto de aquella «curiosa» idea fichteana de aspiración o aproximación infinita, reformulada así: todo ente ha existido previamente dentro de una unión esencial, de modo que cada existencia individual presupone ese único Ser. Somos, por consiguiente --como diría Proclo, enfatizando esa mítica unidad primigenia evocada en el Fedro-- una esencia una y múltiple a la vez. Aspiramos por ello al «reencuentro de todos los espíritus», aunque debamos aceptar que esa unión infinita no puede darse en el tiempo de la conciencia finita, prendida como está de sus estructuras duales ${ }^{29}$.

28 Idem.

29 La carta de Hölderlin a su hermano, fechada en Jena el 13 de abril de 1795, en la que 
Pues bien, a esto llega Hölderlin precisamente en la medida en que hace corresponder a ese Ser en el plano ontológico su imagen de Grecia en el plano de una temporeidad (Zeitigkeit) disruptiva respecto al acontecer histórico habitual. La línea de lectura que hemos venido desplegando aquí sostiene, por tanto, que la imagen de Grecia que se hace Hölderlin, ésa que madura desde los Himnos hasta el Hiperión, es el modelo para su propuesta de un Ser en sentido único y superior, que no se da como se dan las cosas del mundo, pero que tampoco se encuentra esencialmente separado de ellas ni se limita a ser una exigencia subjetiva. Así pues, ¿cómo se dan Grecia y Ser? Se dan como evocación, como anámnesis de algo esencial que antecede, mas no en el orden óntico ni dentro de la secuencia temporal de lo condicionado. Lo que supone asumir que ambas instancias son irrecuperables, esto es, que no cabe eludir el desgarro histórico ni ontológico. Porque sólo justamente en ellos, a través de ellos, transparecen Grecia y el puro Ser, en el sentido único de la palabra. A esta comprensión ayuda una lectura del platonismo que los jóvenes idealistas conjugan con fórmulas como las del famoso Hen kai pan de aire spinociano o el Hen diaferon eauto heraclíteo: un Ser-Uno que se diferencia de sí mismo, en sí mismo diferente. A ese principio unificador, a ese ser previo a la separación, Hölderlin lo nombra en Hiperión como Naturaleza ${ }^{30}$, y concibe su manifestación ejemplar como belleza, en directa remisión a la teoría platónica del eros. Desde el nombre de la protagonista, Diotima, hasta las múltiples recreaciones del mito platónico en las distintas versiones previas de la novela, son constantes las alusiones a diálogos como Banquete o Fedro. ${ }^{31}$ De la forma más explícita, el Prólogo al

le explica una importante característica de la filosofía de Fichte, muestra hasta qué punto hay una reapropiación de su pensamiento por parte del poeta: a la actividad infinita e ilimitada según su propio impulso de un ser con conciencia le es necesaria una limitación, una resistencia, para tener objeto, para poder relacionarse con el mundo, en la misma medida que requiere de esa aspiración a lo infinito. Siendo imposible alcanzar esa meta en la tierra, no habiendo aquí otra vía que la de una aproximación infinita, es precisa la fe en una permanencia infinita (SWB, II, 648; HCC, 241), algo que la intuición intelectual de la belleza permite vislumbrar.

30 Cfr. Stefan Büttner, «Natur - Ein Grundwort Hölderlins», en Hölderlin-Jahrbuch 1988/89, 223-247. Especialmente sugestivas son las consideraciones de Felipe Martínez Marzoa, v.g. en su libro De Kant a Hölderlin (Madrid: Visor, 1992) sobre la lectura que hace Hölderlin de die Natur, distinta de la idea de un principio genético, y su correlación con la cuestión de Grecia, el Ser o Diotima.

31 Non coerceri maximo contineri tamen a minimo divinum est: «es divino no ser abarcado por lo más grande, $\mathrm{y}$, sin embargo, ser contenido por lo más pequeño». Esta frase, dedicada a San Ignacio de Loyola en un epitafio simbólico incluido en la Imago primi saculi Societatis Iesu (una obra conmemorativa de la Compañía de Jesús para celebrar su primer centenario en 1640), que Hölderlin menciona en el prefacio del Fragmento de Hiperión y toma también como motto en la versión definitiva de la novela, viene a resumir su esfuerzo de leer conjuntamente a Kant y los griegos. Por una parte, en ella resuenan las categorías de lo bello (contención armónica 
Segmento de una penúltima versión de la novela, redactado en otoño de 1795 , declara lo siguiente:

«Todos nosotros recorremos una órbita excéntrica, y no hay ningún otro camino posible de la infancia a la perfección.

La venturosa concordia, el ser, en el sentido único de la palabra, está perdido para nosotros, y teníamos que perderlo si es que debíamos aspirar a él, conquistarlo luchando. Nos separamos del apacible Hen kai pan (Uno y Todo) del mundo para producirlo por nosotros mismos. Estamos enemistados con la Naturaleza, y aquello que antaño, como puede creerse, era uno, se halla ahora en conflicto, y el dominio y la servidumbre se alternan en ambas partes. A menudo nos parece como si el mundo lo fuese todo y nosotros nada; pero a menudo también es como si nosotros lo fuéramos todo y el mundo, nada. También Hiperión se dividía entre ambos extremos.

Acabar ese eterno combate entre nosotros mismos y el mundo, restituir la paz de toda paz que a toda razón supera, unirnos con la Naturaleza en un todo infinito, ése es el objeto de todo afán nuestro, nos pongamos o no de acuerdo.

Pero ni nuestro saber ni nuestro actual alcanzan en periodo alguno de la existencia el punto en el que todo conflicto cesa, en el que Todo es uno; la línea definida sólo se une con la indefinida en una aproximación infinita.

No tendríamos ninguna idea de esa paz infinita, de ese ser, en el sentido único de la palabra, no aspiraríamos a unir la Naturaleza con nosotros, no pensaríamos ni actuaríamos, no habría absolutamente nada (para nosotros), incluso nosotros no seríamos nada (para nosotros) si no existiera, no obstante, esa unión infinita, ese ser, en el sentido único de la palabra. Existe --como belleza; nos aguarda, por decirlo con palabras de Hiperión, un nuevo reino, donde la belleza será la reina.-

Yo creo que al final todos diremos: ¡Perdona, Santo Platón! Se ha pecado gravemente contra ti».

El pecado contra el sagrado Platón -- o divino: divus Plato, como lo llama Ficino-- consiste justamente en haberlo leído en los términos abstractos, separadores, del entendimiento; en haber tomado su mundo de las ideas como un trasmundo; en haber separado lo ideal de este mundo real y no haber comprendido que el proceso de la vida es el de un círculo espiritual donde todo está conectado ${ }^{32}$. Esta pertenencia común a la totalidad concordante de la vida

en límites) y lo sublime (desbordar lo máximo y no ser abarcado por ello). Por otra, resuena la dialéctica platónica de los principios de lo grande y lo pequeño (Filebo, Timeo), así como la tarea de mediar los extremos que corresponde a quien, como eros, procede del doble linaje de Poros (sobreabundancia) y Penía (indigencia).

32 Dejamos apuntada una posible resonancia de esta concepción neoplatónica del círculo 
es lo que eros hace recordar al alma. Influido por su amigo el poeta durante su estancia compartida en Frankfurt, entre 1797 y 1799 Hegel compondrá sobre este modelo su propia filosofía de la Unificación, nucleada en torno a los conceptos de Vida, Amor y Religión. En ese sentido escribirá entonces: «Platón, para representar al espiritu, es decir, lo divino fuera de su limitación, por un lado, y la comunidad de lo limitado con lo viviente, por el otro, separa lo que es vida pura de lo limitado mediante una diferencia en el tiempo: representa asi los espíritus puros como si hubieran vivido por entero en la contemplación de lo divino y luego en la vida terrenal sólo existieran con la conciencia oscurecida de aquello» ${ }^{33}$. Según esta explicación, lo que el amante «recuerda» en la intuición erótica de la unión esencial con el amado no es una vida propia anterior en otro mundo, sino la unidad previa de la Vida misma que los constituye a ambos. Eros, funcionando aquí como fundamento y mediación a un tiempo, hace descubrir a los amantes una dimensión más esencial de su ser que permanecía oculta: justamente ese puro ser, en el sentido único y más alto de la palabra.

Del mismo modo lo entenderá Hölderlin. Lo que tiende a expresar bajo el nombre de Grecia es, de forma cada vez más acusada, la experiencia de lo divino y lo trágico de consuno, de tal manera que su pérdida funciona como cifra de la finitud -- pero, eso sí, al modo de un estar desgarrado que no aleja ni del absoluto, del Uno-Todo, ni de la esperanza en el dios venidero: ése que en uno de sus poemas más deslumbrantes, Pan y Vino, se muestra como Dionisos y Cristo a un tiempo, dios hecho hombre cuyo sacrificio invita a la reditio del alma, al regreso a la verdadera patria. Los dioses de Grecia dejan entonces de ser recuerdo de un pasado, dejan de ser objeto historiográfico o tema meramente «literario», como lo son para los «poetas hipócritas», que no creen en lo divino, y pasan a ser aquello que transciende y no es referible como un ente en presencia, pero que está en el poema, que se vivencia en él. Por eso, en su dimensión más honda, el poema es para Hölderlin algo así como una eucaristía donde el poeta-sacerdote hace la invocación en virtud de la cual pan y vino se transforman, se transustancian en carne y sangre del dios. Esta fe poética agudizada en los grandes himnos de madurez es, en el fondo, la manera en que Hölderlin ha llegado a incorporar el salto mortale jacobiano. Pues no hay en la deriva del idealismo alemán un mero reniego de Jacobi, al contrario: se asume su advertencia de que el kantismo debería ser revisado si es que no quiere acabar en nihilismo, en una inmanencia estéril, incapaz de generar su propio transcendimiento. ¿Cómo quedarse sin más con el mundo aparente, insustancial, despoblado de belleza y de otros signos de lo divino?

espiritual en la idea hölderliniana de una órbita excéntrica, que a su vez recoge el sentido místico de la vía ignaciana.

33 HEJ, p. 357. 
Llegados a este punto, es preciso enunciar de forma sintética algunas conclusiones que cabe extraer de la reconstrucción interpretativa que hemos esbozado aquí. Sin duda, hace ya tiempo que la investigación especializada viene dibujando una trayectoria del idealismo alemán mucho más rica y compleja que la que se desprende de la mera secuencia canónica Kant-Fichte-SchellingHegel, entendida además con demasiada frecuencia como simple peraltación de una filosofía de la conciencia. Aun así, nos atreveríamos a decir que todavía está por sondear buena parte de la explosividad filosófica que alberga el pensamiento hölderliniano a propósito de todas estas cuestiones. De la mano de Hölderlin, por ejemplo, es posible comprender de forma mucho más intensa cómo toda esta presunta metafísica de la subjetividad se deconstruye desde dentro en varios sentidos: para empezar, incluso ahí donde se redimensiona el paradigma de la conciencia, como es el caso de Hegel, se abandona drásticamente el modelo monológico y se apuesta por una intersubjetividad dinámica, que tiende a resolver en proceso sus restos sustancialistas. La idea de un Ser previo a la escisión sobrepuja asimismo la lectura ontoteológica del idealismo practicada por Heidegger, y lo hace en un sentido que excede su propio rescate de Hölderlin como caso aparte. Por lo demás, como ya hemos indicado en más de una ocasión a lo largo de este trabajo, que lo infinito sea inherente al despliegue de lo finito es un pensamiento que, pese a lo dictado por la vulgata hegeliana, invita a cuestionar la validez de una intelección de este proceso de las ideas modernas como mera secularización.

Pero, sobre todo, la manera en que Hölderlin y Hegel, desde sus años de formación hasta los de su estancia común en Frankfurt, han ido incorporando un bagaje platónico y neoplatónico a sus primeras propuestas filosóficas evidencia la genuina riqueza especulativa del fondo dialógico ${ }^{34}$, antes que dialéctico, de todo este naciente idealismo alemán. En concreto, según hemos tratado de exponer aquí, redimensiona el concepto platónico de rememoración como un dispositivo que remite la historicidad a algo que desborda su secuencia lineal, tal como remite la conciencia a algo que no es la identidad sustantiva de un yo que practica un cierre reflexivo sobre sí, y al que ni los propios recuerdos ni la experiencia vivida ni el encuentro con el otro alteran en esencia.

Por el contrario, en el contexto de la filosofía de la Unificación se rompe la ilusión teorética que lleva a pensar que el yo se reduce a esa representación objetivada de la autoconciencia. Por eso, lo que la crítica hölderliniana del

34 No suele repararse demasiado en el hecho de que la adopción de la forma epistolar tanto en buena parte de la novelística de la época —así, por ejemplo, en Hiperión - cuanto en su literatura filosófica, repleta de "Cartas", guarda un parentesco innegable con la forma dialogada de la escritura platónica, en consonancia además con el "symphilosophieren" propio del romanticismo temprano. 
esbozo ensayístico Juicio y Ser sugiere es la idea de que el yo no puede nunca coincidir por entero y agotarse en la autoconciencia. Con ello cambia a fondo la manera de concebir la relación entre el sujeto y la memoria propiciada por esa falta de conciencia histórica que es común al primer racionalismo y que todavía lastra a la filosofía transcendental. Se pone así en cuestión la concepción de un yo que tiene recuerdos tal como cabría decir que tiene objetos o representaciones del mundo externo, y que es una concepción que tiende a una objetivación del recuerdo y la memoria, esto es: tiende a hacer de los recuerdos un objeto que el yo tiene, pero no como algo que le resulte inherente ni que lo constituya, sino más bien como algo que puede tener o no. Según este modo de ver las cosas, la relación del sujeto con su recuerdo se expresa en la forma de una proposición, conforme a la estructura típica del juicio del entendimiento, basada en la separación de sujeto y objeto.

Pero lo que tiene en mente Hölderlin al recurrir a la anámnesis platónica es otra cosa bien distinta: al acordarse (Platón dice míticamente: al rememorar aquello que el alma vio en otro mundo), el yo ve desbordada su identidad sustantiva, su cierre reflexivo, y en ese momento de reconocimiento, que en su caso corresponde a la intuición intelectual, conoce a otro como siendo yo, de modo que su identidad viene a saberse descansando propiamente en una unidad previa. El sentimiento de la belleza despierta esa experiencia anterior de la unidad concordante de la vida, y sólo por ella cabe captar una cierta circularidad o autorreferencialidad más originaria, que, con todo, se da siempre de manera aproximativa, nunca concluyente. Con ello se compadece la idea de un yo que experimenta la imposibilidad de clausurarse en una conciencia transparente por completo a sí misma y que, en cambio, despliega una autorreferencialidad excéntrica, como la del personaje de la novela Hiperión, de índole muy distinta a la de aquel sujeto fundante, estable y permanente que el idealismo alemán heredó en su arranque, problemáticamente, de la filosofía anterior, en tanto filosofía de la subjetividad transcendental. Aquí, el recuerdo ya no queda como algo extrínseco, que deja inalterada a esa identidad fuerte de un yo constante. Al contrario, en esta experiencia del recuerdo de sí, la subjetividad experimenta algo similar a ese choque o contragolpe (Gegentoss) del que habla Hegel cuando se refiere al modo en que ha de leerse filosóficamente una proposición especulativa en el Prólogo de la Fenomenología del Espíritu. Si allí, poniendo el ejemplo de la proposición «Dios es el Ser», Hegel señalará la limitación del entendimiento al tomar el sujeto como un punto fijo al cual se adhieren los predicados, cuando lo cierto es que la esencia viva de lo mentado se descubre cabalmente en el predicado, lo que se verifica en esta otra forma de concebir el recuerdo es que éste pasa al interior del sujeto, recomponiéndolo, y no queda como pura exterioridad. Dicho de otro modo: al abrirse la experiencia vivida de lo que somos a un pasado latente (a ese fondo de proveniencia que es 
un pozo nocturno, diría Derrida), el sujeto se abre al mismo tiempo al mundo y disuelve su costra de fijeza inalterable. Esta costra que se disuelve y deja que aflore una subjetividad más amplia, más viva y espiritual, es como la de las alas que cubren la espalda del enamorado en el mito del Fedro: la flor del alma se abre y es entonces cuando puede avistarse, por encima de la limitada visión del sentido común, el Uno en nosotros.

Así, aun con toda la nueva mitología de lo incondicionado, todavía bajo las formas sublimadas de la intuición intelectual, comienza a explorarse aquí una nueva manera de pensar lo real que acabará sobrepasando el modelo de la presencia. En fin: mediante esta fructífera interpretación del platonismo, en vez de concebir la identidad del yo como una cosa que siempre permanece abstractamente igual sí misma, a lo que apunta este momento germinal del idealismo alemán es a la idea de una mismidad dinámica, en construcción a través de un proceso de reconocimiento que pasa por un extrañamiento previo, propiciado justamente al recordarse como otra de sí en su mera actualidad. Cabe sospechar si en el Hegel de madurez el movimiento de la Erinnerung, decantado hacia una interiorización reflexiva donde todo pasado queda subsumido en un presente omnienglobador, no ha recaído en los modos de una automanifestación del absoluto que anula la contingencia de lo finito. Pero en Hölderlin parece evidente que la quiebra de la representación habitual de las formas de constitución del yo y de su experiencia del tiempo lo aboca a un discurso bien distinto al de la filosofía de la historia convencional, del que todavía podemos seguir extrayendo alguna que otra instructiva lección.

Manuel Barrios Casares es Catedrático de Filosofía de la Universidad de Sevilla.

Lineas de investigación

Romanticismo alemán, Nietzsche

Últimas publicaciones

Barrios, M., Abrazando al caballo. Aspectos de la relación entre Nietzsche, el nihilismo y las vanguardias, Estudios Nietzsche: Revista de la Sociedad Española de Estudios sobre Friedrich Nietzsche, 2014.

Barrios, M., Expresividad e intersubjetividad: apuntes de para una critica hegeliana del yo posmoderno, Contrastes No 15, 1, pp. 297 - 306, 2010.

Email: mbarrios@us.es 
